Hydrol. Earth Syst. Sci., 15, 2839-2852, 2011

www.hydrol-earth-syst-sci.net/15/2839/2011/

doi:10.5194/hess-15-2839-2011

(C) Author(s) 2011. CC Attribution 3.0 License.

\title{
On the use of AMSU-based products for the description of soil water content at basin scale
}

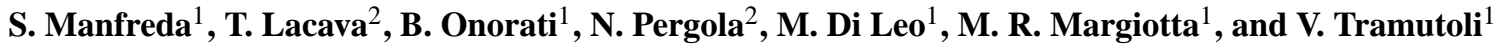 \\ ${ }^{1}$ Department of Physics and Environmental Engineering, University of Basilicata, Potenza, Italy \\ ${ }^{2}$ Institute of Methodologies for Environmental Analysis, National Research Council, Tito Scalo, Italy
}

Received: 19 May 2011 - Published in Hydrol. Earth Syst. Sci. Discuss.: 27 May 2011

Revised: 24 August 2011 - Accepted: 29 August 2011 - Published: 9 September 2011

\begin{abstract}
Characterizing the dynamics of soil moisture fields is a key issue in hydrology, offering a strategy to improve our understanding of complex climate-soil-vegetation interactions. Besides in-situ measurements and hydrological models, soil moisture dynamics can be inferred by analyzing data acquired by sensors on board of airborne and/or satellite platforms. In this work, we investigated the use of the National Oceanic and Atmospheric Administration - Advanced Microwave Sounding Unit-A (NOAA-AMSU-A) radiometer for the remote characterization of soil water content. To this aim, a field measurement campaign, lasted about three months (3 March 2010-18 May 2010), was carried out using a portable time-domain reflectometer (TDR) to get soil water content measures over five different locations within an experimental basin of $32.5 \mathrm{~km}^{2}$, located in the South of Italy. In detail, soil moisture measurements were carried out systematically at the times of satellite overpasses, over two square areas of $400 \mathrm{~m}^{2}$, a triangular area of $200 \mathrm{~m}^{2}$ and two transects of 60 and $170 \mathrm{~m}$, respectively. Each monitored site is characterized by different land covers and soil textures, to account for spatial heterogeneity of land surface. Afterwards, a more extensive comparison (i.e. analyzing a $5 \mathrm{yr}$ data time series) was made using soil moisture simulated by a hydrological model. Measured and modeled soil moisture data were compared with two AMSU-based indices: the Surface Wetness Index (SWI) and the Soil Wetness Variation Index (SWVI). Both time series of indices have been filtered by means of an exponential filter to account for the fact that microwave sensors only provide information at the skin surface. This
\end{abstract}

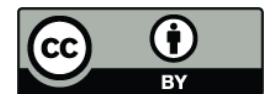

Correspondence to: S. Manfreda (salvatore.manfreda@unibas.it) allowed to understand the ability of each satellite-based index to account for soil moisture dynamics and to understand its performances under different conditions. As a general remark, the comparison shows a higher ability of the filtered SWI to describe the general trend of soil moisture, while the SWVI can capture soil moisture variations with a precision that increases at the higher values of SWVI.

\section{Introduction}

Soil moisture (SM) is a fundamental variable in a large number of applications including flood forecasting, numerical weather prediction, agricultural drought assessment, water resources management, etc. Its importance has been stressed by several authors in all water related issues. For instance, the soil moisture state as well as its spatial distribution are controlling factors for both the infiltration process and the catchment response, especially in small and medium-sized basins (Merz and Plate, 1997; Hino et al., 1988; Schulze, 2000; Castillo et al., 2003; Meyles et al., 2003; Scipal et al., 2005; Blume et al., 2009; Manfreda, 2008).

The Global Climate Observing System (GCOS) has recently included soil moisture in the list of the Essential Climate Variables (ECVs) (GCOS-138, 2010) confirming the relevance of such a parameter at a global scale and also increasingly stimulating the research to invest on intensive field measurements campaigns in order to better understand the complex dynamics of SM in space and time domains. As a consequence, SM measurements would be extremely useful especially if performed with high sampling frequency, over large areas and with a good level of accuracy.

Published by Copernicus Publications on behalf of the European Geosciences Union. 
The measurement of soil water content is still difficult and expensive, because most techniques are punctual and provide indirect measures (e.g., TDR, FDR, Tensiometers). The gravimetric soil sampling is the only direct method for estimating the total water content of soils, but it is time consuming. In fact, this method is generally used to calibrate other techniques. In this contest, a major source of data may come from the information collected by satellites, for their ability of investigating, at very large scale (Troch et al., 1997), not only SM but also vegetation cover (Dobson and Ulaby, 1998; Jackson and Vine, 1996), both relevant in hydrological applications.

In recent years, the capability of Earth Observation (EO) systems to provide reliable SM measurements has been largely investigated. One of the main advantages of the remote sensing approach, as far as passive systems are considered, is the availability in near real time of quasi-continuous data, useful to perform frequent mapping, early warning, prediction and forecasting activities. Although remote sensing provides information on a large spatial scale, it is only applicable to the skin layer of the soil surface, and is unable to analyze the deepest layers. Concerning the capabilities of satellite passive radiometers, an intensive measurement campaign was conducted by the Electronically Scanned Thinned Array Radiometer (ESTAR) during the Southern Great Plains 1997 (SGP97) (Famiglietti et al., 1999) testing the use of passive microwave remote sensing to measure the surface wetness (Jackson et al., 1999). In the last decade, data acquired by microwave sensors, both active and passive, have been gathered confirming their potential in providing detailed information about SM variability in the space-time domain (Calvet et al., 2010). The launch of Soil Moisture and Ocean Salinity mission (SMOS) in November 2009, an ESA (European Space Agency) dedicated soil moisture mission, clearly indicates the need and the will of the international scientific community to have a better SM estimation from satellite (Kerr et al., 2001; Kerr, 2007; Kerr et al., 2010).

Furthermore, in-situ SM observations are needed to evaluate SM products derived from satellites (Albergel et al., 2010; Pasolli et al., 2011). Several in-situ SM measurement campaigns have been carried out waiting for SMOS launch and operational status (Camps et al., 2004; Vall-llossera et al., 2005; Rosnay and Calvet, 2006; Calvet et al., 2007; Panciera et al., 2008; Zribi et al., 2010), as well as to validatecalibrate data acquired by other satellite-based microwave sensors (Njoku et al., 2002; Jackson and Cosh, 2003; Jackson et al., 2005, 2006; Colliander et al., 2010). This considerable quantity of information is extremely useful for the assessment of the potential of every satellite product in any observation condition at a global scale as well as to evaluate models performances (Albergel et al., 2010). This makes the development of a Global Terrestrial Network for Soil Moisture (GTN-SM), with a set of in situ stations with standard measurement protocols, data quality assurance strategies and archiving procedures (GCOS-138, 2010), a crucial point.
The International Soil Moisture Working Group under GEWEX (Global Energy and Water Cycle Experiment), along with the CEOS (Committee on Earth Observation Satellites) Working Group on Calibration and Validation, have strongly contributed to the establishment of an integrated global soil moisture observing system as part of the Global Earth Observation System of Systems (GEOSS), as envisaged by the Group on Earth Observation (GEO). The data hosting center "International Soil Moisture Network (ISMN)" has been established with the financial support of ESA and it is operated by the Vienna University of Technology (ESA, 2010; Dorigo et al., 2011).

Within this framework, we further investigated the ability of Advanced Microwave Sounding Unit-A (AMSU-A) sensor, the radiometer aboard National Oceanic and Atmospheric Administration (NOAA) polar satellites series since 1998, in investigating SM variations. In a recent study (Lacava et al., 2010), in fact, the capability of this sensor (onboard NOAA-15) for SM estimation has been assessed through a comparison of two AMSU-based SM indices with both in-situ and simulated data for the Upper Tiber river catchment (i.e. in Umbria region). To better assess the reliability of the AMSU-based SM indices, as well as to verify the independence of the obtained results from a specific geographic location, the observational and environmental conditions, in this work SM AMSU retrievals have been compared with both in-situ observations and modeled SM for a specific site located in Basilicata Region (southern Italy). This site in fact, is characterized by dryer climate and different soil and vegetation respect to the previous case study.

AMSU-A sensor provides data at a resolution of about $20 \mathrm{~km}$, but with high frequency (i.e. one pass every $12 \mathrm{~h}$ at mid latitudes). This means that it may not be used to interpret spatial variability of SM at the basin scale, but it may provide a good description of the its temporal fluctuations. Previous works (e.g. Lacava et al., 2010) have underlined the ability of such product to describe the seasonal fluctuation of SM, but it would be more interesting to understand if, and to what extent, AMSU-based indices are able to describe short time fluctuations of SM. This paper try to tackle this problem and provides a strategy for the use of AMSU data.

To reach the scope of the paper, soil moisture information achieved by exploiting AMSU-A data acquired by NOAA 18 satellite were first compared with in-situ measurements achieved by a field campaign lasted three months (MarchMay 2010). After the intercomparison with direct measurements, a more robust long-term comparison was performed over a period of $5 \mathrm{yr}$ (2006-2010) by using simulated data obtained applying the hydrological Distributed model for Runoff Et Antecedent soil Moisture simulation (DREAM) (Manfreda et al., 2005).

The paper introduces the methods and techniques adopted within this work in Sect. 2. Section 3 provides a description of the data and finally in Sect. 4, results of these analysis will be presented and discussed. 


\section{Methods}

\subsection{The AMSU-based soil wetness indices}

The AMSU-A is a cross-track scanning total power radiometer. It is divided into two physically separate modules, each of which operates and interfaces with the spacecraft independently. Module A- 1 contains 13 channels $(23.8 \mathrm{GHz}-$ $57.3 \mathrm{GHz}$ ) and Module A-2 contains two additional channels $(57.3 \mathrm{GHz}$ and $89.0 \mathrm{GHz})$. The sensor has a maximum scan angle of $\pm 59.5^{\circ}$ and a swath of about $2.343 \mathrm{~km}$ width from the $833 \mathrm{~km}$ nominal orbital altitude. The nominal spatial resolution at nadir is $50 \mathrm{~km}$, but during the processing, AMSUA data are re-mapped at $20.0 \mathrm{~km}$.

In the present work, two different SM indices have been generated from AMSU-A data. Their potential in providing information about SM is related to the specific spectral features of AMSU-A. Some AMSU channels, in fact, being localized in atmospheric windows (those at 23.8, 31.4, $50.3,89$ and $150 \mathrm{GHz}$, respectively), are able to provide information about surface parameters, such as SM. In particular, due to the different emissivity of dry and wet soils in the microwave region, a combination of measurements achieved at high and low AMSU frequencies may give a qualitative estimation about variations in surface SM (Grody et al., 2000; Gu et al., 2004; Kongoli et al., 2006; Lacava et al., 2010). Starting from these considerations, the Surface Wetness Index (SWI) is defined as:

SWI $(x, y, t)=\mathrm{BT}_{89}(x, y, t)-\mathrm{BT}_{23}(x, y, t)$

where $t$ is the acquisition time, $(x, y)$ are the geographic coordinates of the pixel center, $\mathrm{BT}_{89}$ is the radiance (expressed in Brightness Temperature) measured in channel 15 (at $89 \mathrm{GHz}$ ) and $\mathrm{BT}_{23}$ is the same quantity, but measured in channel 1 (at $23 \mathrm{GHz}$ ). Positive values of such an index should indicate a high soil water content within the instantaneous field of view (IFOV) of the sensor. As soil wetness increases the decrease in emissivity is enhanced at lower frequencies, so that the emissivity difference at low and high frequencies increases as well (Basist et al., 1998; Singh et al., 2005).

In order to reduce the effects arising from the presence of vegetation, roughness and/or permanent water within the IFOV, Lacava et al. (2005) proposed a standardized version of SWI, the Soil Wetness Variation Index (SWVI):

$\operatorname{SWVI}(x, y, t)=\frac{\operatorname{SWI}(x, y, t)-\mu_{\mathrm{SWI}}(x, y)}{\sigma_{\mathrm{SWI}}(x, y)}$

being $\mu_{\mathrm{SWI}}(x, y)$ and $\sigma_{\mathrm{SWI}}(x, y)$ the monthly mean and standard deviation of SWI respectively (i.e. the reference fields). These parameters are computed following the Robust Satellite Techniques (RST) approach proposed by Tramutoli $(1998,2007)$, based on a homogeneous multi-annual data-set of AMSU-A images. The latter are collected during the same calendar month of the year and approximately at the same hour of the day of the image at hand. The SWVI gives an estimation of relative, rather than absolute, SWI variations. Generally speaking, assuming that vegetation and roughness effects may be considered constant within a 1-month temporal window, high values (in modulus) of SWVI should indicate a relative variation in SM at each specific location and in particular, positive SWVI values indicate soil conditions wetter than those expected in unperturbed conditions. For its construction SWVI is a standardized variable having a Gaussian behaviour, characterized by mean value $\approx 0$ and standard deviation $\approx 1$. This means that about $96 \%$ of the measured SWVI at a specific location $(x, y)$ is included in the range $-2<$ SWVI $<2$. Hence, SWVI values within that interval have a significant higher frequency of occurrence and account for the "normal" fluctuations of the considered signal because of the variations of observational, atmospheric and illumination conditions.

\subsection{Data filtering}

Information about SM achievable by microwave satellite data is directly related to the surface soil layer $(0.2-5 \mathrm{~cm})$ (Escorihuela et al., 2010), while in-situ observation are usually referred to a deeper layer. So that every time they are compared it is necessary to transfer surface information to the soil profile. One way is to use data assimilation models that explicitly account for the infiltration process into the deeper layer using measured climatic forcing (e.g. Margulis et al., 2002).

A simplified scheme is represented by the semi-empirical approach proposed by Wagner et al. (1999), also referred to as exponential filter, that only requires the calibration of one parameter for its application (e.g. Brocca et al., 2009). Such a method was employed for this purpose:

$X^{*}(t)=\frac{\sum X\left(t_{n}\right) \exp \left(\frac{-\left(t-t_{n}\right)}{T}\right)}{\sum \exp \left(\frac{-\left(t-t_{n}\right)}{T}\right)}$

where $X\left(t_{n}\right)$ is the SM index retrieved from AMSU (SWI and SWVI), $X^{*}(t)$ is the filtered SM index (thus obtaining SWI* and SWVI*), $t_{n}$ is the acquisition time of $X\left(t_{n}\right)$ and $T$ is the characteristic time length parameter to be calibrated. The obtained SWI* and SWVI* indices are thus representative of a deeper soil layer and, hence, more comparable with ground measurements and modelled SM data.

\subsection{Soil moisture modelling by DREAM model}

To extend the period of investigation of the experimental field campaign, we adopted a hydrological model to describe multi-year SM fluctuations. DREAM (Distributed model for Runoff Et Antecedent soil Moisture simulation), introduced by Manfreda et al. (2005), is a semi-distributed hydrological model suitable for continuous simulations. The main hydrological processes are computed on a grid-based representation of the river basin that takes into account the spatial 
heterogeneity of hydrological variables using a digital elevation model, soil and vegetation grid-maps. Canopy cover determines the amount of rainfall intercepted by vegetation before hitting the soil surface. Throughfall (precipitation minus interception) is initially stored in surface depressions; net precipitation (throughfall minus depression storage) is then subdivided in surface runoff and infiltration into the soil; soil water content, which is the limiting factor of evapotranspiration from vegetation, is redistributed within each subcatchment according to the morphological structure of the basin exploiting the wetness index proposed by Beven and Kirkby (1979). Groundwater recharge is obtained as percolation through the vadose zone and it is routed as a global linear reservoir. DREAM applied at daily time-step requires the calibration of only one parameter, thanks to a robust and physically based parametrization, which allows for an extensive use of a priori information. The DREAM model was successfully tested in several medium-size basins, exhibiting considerable differences in climate and other physical characteristics (e.g., Manfreda et al., 2005; Fiorentino et al., 2007). In the present study, DREAM model has been applied over a time window of about $5 \mathrm{yr}$, using data recorded from January 2006 to September 2010. It is important to underline that for this modeling application, we paid particular attention to the estimation of the evapotranspiration fluxes that are the main responsible of SM dynamics during the drying phases. The potential evapotranspiration was estimated using the Penman-Monteith equation modified by the FAO (Allen et al., 1998). Effects of basin morphology were incorporated in the computation using the analytical algorithm developed by Allen et al. (2006) for the estimation of the incident solar radiation, that affects evapotranspiration as well as snowmelt, taking into account both aspect and slope of the surface.

SM is computed in each grid cell of the basin, assuming uniform soil water content over the root profile. As a consequence the estimated SM values refer to a control volume that changes from site to site assentially according to the vegetation cover and ranges from 50 up to $180 \mathrm{~cm}$ of depth. The relative saturation of the basin is obtained averaging the relative saturation $\theta / n$, where $\theta$ is the soil water content and $n$ is the soil porosity) of the basin grid cells. This time series, multiplied by the mean porosity of the soils of the basin, provides a description of the soil moisture dynamics over a larger spatial scale (basin-scale $32.5 \mathrm{~km}^{2}$ ). This scale is still smaller than the resolution of AMSU-A sensor $(20 \mathrm{~km})$, but certainly is better suited for such comparison respect to point measurements.

\section{Study area and experimental setup}

The monitoring campaign was carried out over the experimental river basin "Fiumarella of Corleto" located in Basilicata region (Southern Italy). It is a tributary of the Sauro river (Agri basin) and has an area of $32.5 \mathrm{~km}^{2}$. The basin is placed in a sub-humid climatic zone with mean annual rainfall of approximately $720 \mathrm{~mm}$ and characterized by hot-humid summers and chilly to mild winters. A general description of the basin is given in Fig. 1, where the geographical location of the basin and its experimental setup are described. There, some details regarding the permanent monitoring system as well as the location of the sites monitored during the field campaign, are also given.

For the study area a high resolution LiDAR DEM $(1 \times 1 \mathrm{~m})$ is available, which has been used to characterize the morphology of the investigated sites (see Fig. 1) as well as for the modeling application described in Sect. 2.3. Catchment pedology was investigated through field campaigns and laboratory measurements aimed at identifying the main soilland units of the basin. These data were reported in the land cover map elaborated by Santini et al. (1999) that was there after used by Carriero et al. (2007) to define the soil hydraulic properties of each unit. Such an analysis was used in the rainfall-runoff application that requires accurate information about the spatial variability of soils (Romano and Santini, 1997; Romano and Palladino, 2002).

In situ measurements of soil moisture have been carried out using a portable two-wire connector-type Time Domain Reflectometer (TDR) produced by E.S.I. (Environmental Sensors Inc.). TDR probes were connected with a $2.5 \mathrm{~m}$ long coaxial cable to the TDR instrument. Measurements were acquired at $0-30 \mathrm{~cm}$ depth, in five experimental sites (A, B, C, D, and E in Fig. 1) characterized by different land cover and soil textures. This last choice was made in order to account for the spatial heterogeneity existing within the basin area. In fact, these sites have been identified selecting the most representative land-soil units of the basin. In particular, the site A is located in a silt loam soil covered by grass and shrubs (this unit covers an area of $3.1 \mathrm{~km}^{2}$ ), B in a silt clay soil covered by woody vegetation (unit area of $5.9 \mathrm{~km}^{2}$ ), $\mathrm{C}$ is in a clay loam soil with woody vegetation(unit area of $3.9 \mathrm{~km}^{2}$ ), D is located in silt loam soil (unit area of $0.4 \mathrm{~km}^{2}$ ), and finally the site $\mathrm{E}$ is in a silt loam soil with agricultural land use (crop) (unit area of $6.8 \mathrm{~km}^{2}$ ).

The sampling scheme adopted was modified according to the local morphology, using squares (with $3 \times 3$ points) over gentle slopes or flat surfaces and transects in the case of steep slopes. In detail, we identified three sites with a gentle slope or flat (called Monte Caperrino, Masseria Falcone and the basin outlet) and two transects (named Transect 1 and Masseria Potenza) that are characterized by a mean slope of about 15-18\%. The sampling scheme adopted in each site is shown in Fig. 1. Measurements on Monte Caperrino and Masseria Falcone sites were made over a $3 \times 3$ regular grid composed of 9 points with $10 \mathrm{~m}$ spacing. The measurements at the site close to the basin outlet were made in 3 nodes given the difficulties due to the alluvial material that makes more difficult the probes penetration into the soil. The two transects have been located in two slopes with opposite aspects. The Transect 1 , located on the hydraulic right side 

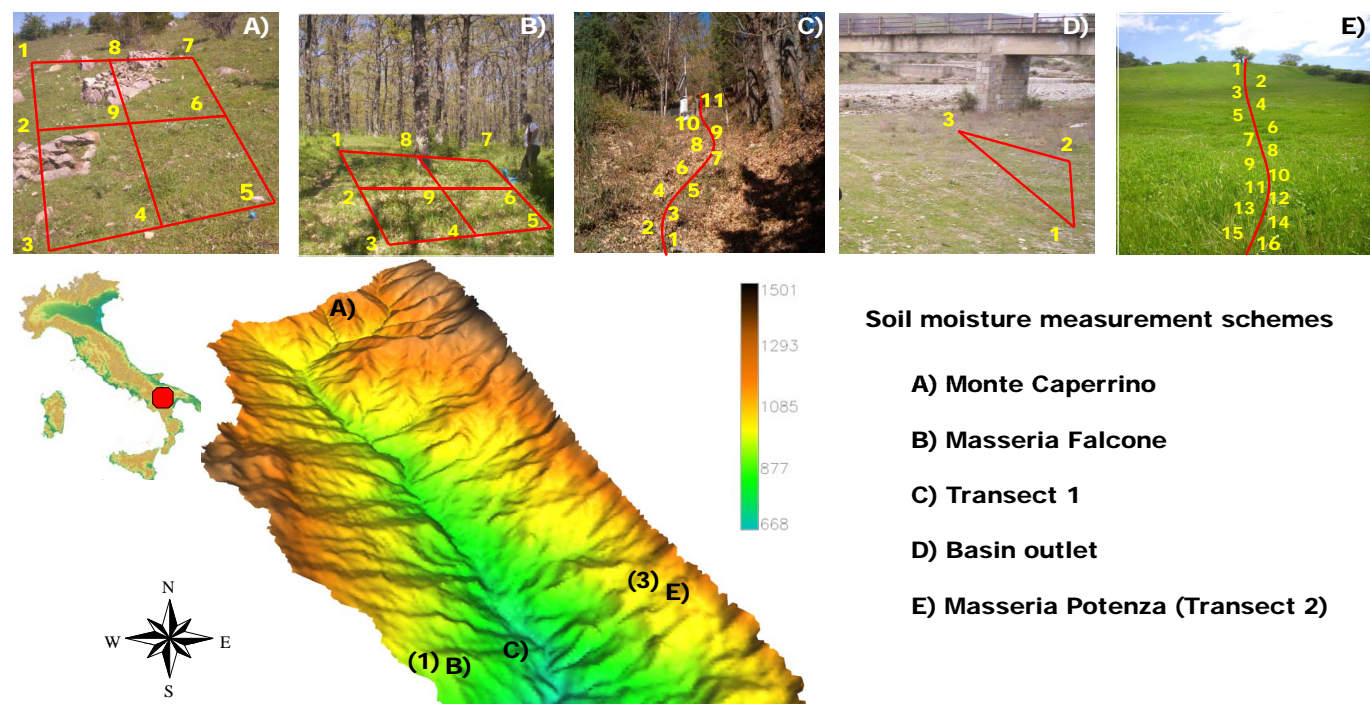

Soil moisture measurement schemes

A) Monte Caperrino

B) Masseria Falcone

C) Transect 1

D) Basin outlet

E) Masseria Potenza (Transect 2)

E)

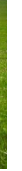

\section{.}


Table 1. Summary of the SM measurements $\mathrm{m}^{3} \mathrm{~m}^{-3}$ obtained using the portable TDR during the period 3 March 2010 to $18 \mathrm{May} 2010$.

\begin{tabular}{|c|c|c|c|c|c|c|c|c|}
\hline & \multicolumn{2}{|c|}{3 Mar 2010} & \multicolumn{2}{|c|}{15 Mar 2010} & \multicolumn{2}{|c|}{17 Mar 2010} & \multicolumn{2}{|c|}{22 Mar 2010} \\
\hline & mean & $\min -\max$ & mean & $\min -\max$ & mean & $\min -\max$ & mean & $\min -\max$ \\
\hline M. Caperrino & - & - & - & - & - & - & - & - \\
\hline M Falcone & 0.32 & $0.23-0.37$ & 0.35 & $0.31-0.40$ & 0.37 & $0.31-0.45$ & 0.34 & $0.30-0.44$ \\
\hline Transect 1 & 0.36 & $0.26-0.48$ & 0.38 & $0.19-0.51$ & 0.41 & $0.26-0.55$ & 0.39 & $0.23-0.54$ \\
\hline M. Potenza & 0.42 & $0.25-0.55$ & 0.39 & $0.25-0.53$ & 0.40 & $0.25-0.55$ & 0.34 & $0.21-0.54$ \\
\hline Outlet & 0.28 & $0.26-0.31$ & 0.24 & $0.24-0.25$ & 0.28 & $0.28-0.30$ & 0.28 & $0.26-0.29$ \\
\hline \multirow[t]{3}{*}{ Spatial mean } & \multicolumn{2}{|r|}{0.37} & \multicolumn{2}{|r|}{0.37} & \multicolumn{2}{|r|}{0.39} & \multicolumn{2}{|r|}{0.36} \\
\hline & \multicolumn{2}{|c|}{$26 \operatorname{Mar} 2010$} & \multicolumn{2}{|c|}{29 Mar 2010} & \multicolumn{2}{|c|}{2 Apr 2010} & \multicolumn{2}{|c|}{20 Apr 2010} \\
\hline & mean & $\min -\max$ & mean & $\min -\max$ & mean & $\min -\max$ & mean & $\min -\max$ \\
\hline M. Caperrino & 0.35 & $0.24-0.52$ & 0.32 & $0.24-0.40$ & 0.30 & $0.18-0.51$ & 0.41 & $0.29-0.54$ \\
\hline M. Falcone & 0.33 & $0.27-0.39$ & 0.32 & $0.26-0.38$ & 0.29 & $0.20-0.34$ & 0.38 & $0.29-0.44$ \\
\hline Transect 1 & 0.40 & $0.29-0.53$ & - & - & 0.32 & $0.19-0.45$ & 0.41 & $0.28-0.52$ \\
\hline M. Potenza & 0.39 & $0.20-0.55$ & - & - & 0.34 & $0.23-0.52$ & 0.42 & $0.32-0.53$ \\
\hline Outlet & 0.36 & $0.17-0.55$ & - & - & 0.31 & $0.17-0.54$ & 0.47 & $0.33-0.55$ \\
\hline \multirow[t]{3}{*}{ Spatial mean } & \multicolumn{2}{|r|}{0.37} & \multicolumn{2}{|r|}{0.34} & \multicolumn{2}{|r|}{0.32} & \multicolumn{2}{|r|}{0.41} \\
\hline & \multicolumn{2}{|c|}{26 Apr 2010} & \multicolumn{2}{|c|}{30 Apr 2010} & \multicolumn{2}{|c|}{6 May 2010} & \multicolumn{2}{|c|}{13 May 2010} \\
\hline & mean & $\min -\max$ & mean & $\min -\max$ & mean & $\min -\max$ & mean & $\min -\max$ \\
\hline M. Caperrino & 0.41 & $0.25-0.56$ & 0.37 & $0.28-0.52$ & 0.28 & $0.20-0.48$ & 0.25 & $0.17-0.31$ \\
\hline M. Falcone & 0.35 & $0.28-0.43$ & 0.32 & $0.22-0.37$ & 0.27 & $0.18-0.34$ & 0.28 & $0.20-0.36$ \\
\hline Transect 1 & 0.43 & $0.26-0.53$ & 0.37 & $0.23-0.52$ & 0.28 & $0.13-0.53$ & 0.33 & $0.17-0.52$ \\
\hline M. Potenza & 0.41 & $0.27-0.55$ & 34 & $0.24-0.53$ & 0.26 & $0.18-0.36$ & 0.18 & $0.07-0.26$ \\
\hline Outlet & 0.34 & $0.26-0.51$ & 0.34 & $0.23-0.53$ & 0.29 & $0.12-0.55$ & 0.30 & $0.12-0.54$ \\
\hline \multirow[t]{3}{*}{ Spatial mean } & \multicolumn{2}{|r|}{0.40} & \multicolumn{2}{|r|}{0.35} & \multicolumn{2}{|r|}{0.28} & \multicolumn{2}{|r|}{0.25} \\
\hline & \multicolumn{2}{|c|}{14 May 2010} & \multicolumn{2}{|c|}{18 May 2010} & Tempo & ral Statistics & & \\
\hline & mean & $\min -\max$ & mean & $\min -\max$ & Tem & poral mean & & STD \\
\hline M. Caperrino & 0.24 & $0.13-0.36$ & 0.30 & $0.21-0.36$ & & 0.324 & & 0.062 \\
\hline M. Falcone & 0.24 & $0.16-0.29$ & 0.32 & $0.25-0.38$ & & 0.310 & & 0.039 \\
\hline Transect 1 & 0.31 & $0.18-0.41$ & 0.36 & $0.19-0.53$ & & 0.356 & & 0.044 \\
\hline M. Potenza & 0.15 & $0.05-0.27$ & 0.27 & $0.12-0.38$ & & 0.309 & & 0.090 \\
\hline Outlet & 0.28 & $0.11-0.53$ & 0.33 & $0.21-0.53$ & & 0.337 & & 0.056 \\
\hline Spatial mean & & 0.23 & & 0.31 & & & & \\
\hline
\end{tabular}

computation of SWVI. In particular, for the aim of this work, only diurnal data were taken into account, so the historical AMSU diurnal imagery dataset was used for the identification of the above mentioned reference fields and, hence, for SWVI computation by Eq. (2). In detail, all the images acquired during the morning passes of NOAA 18 (between 12:00 and 14:00 GMT) for every calendar month of the years from 2006 to 2010 was selected (i.e. 5 yr of data analyzed). All pixels potentially affected by rain clouds and snow effects or those acquired at zenith angle $>50^{\circ}$ were discarded during the processing procedures. About 1500 AMSU-A data were processed and used. It should be noted that some gaps were present over the whole period. Besides the above mentioned discards, failures at the IMAA satellite ground station, NOAA 18 acquisition problems as well as NOAA-19 overlapping effects may be other causes of missing data.

\section{Results and discussion}

In this section, results of the comparison between AMSUderived soil moisture indices (SWI and SWVI) and both insitu $\left(\mathrm{SM}_{\text {in situ }}\right)$ and modeled $\left(\mathrm{SM}_{\text {mod }}\right)$ soil moisture data are discussed in detail. As already mentioned, the first index is supposed to mimic the real dynamics of SM, while the latter 

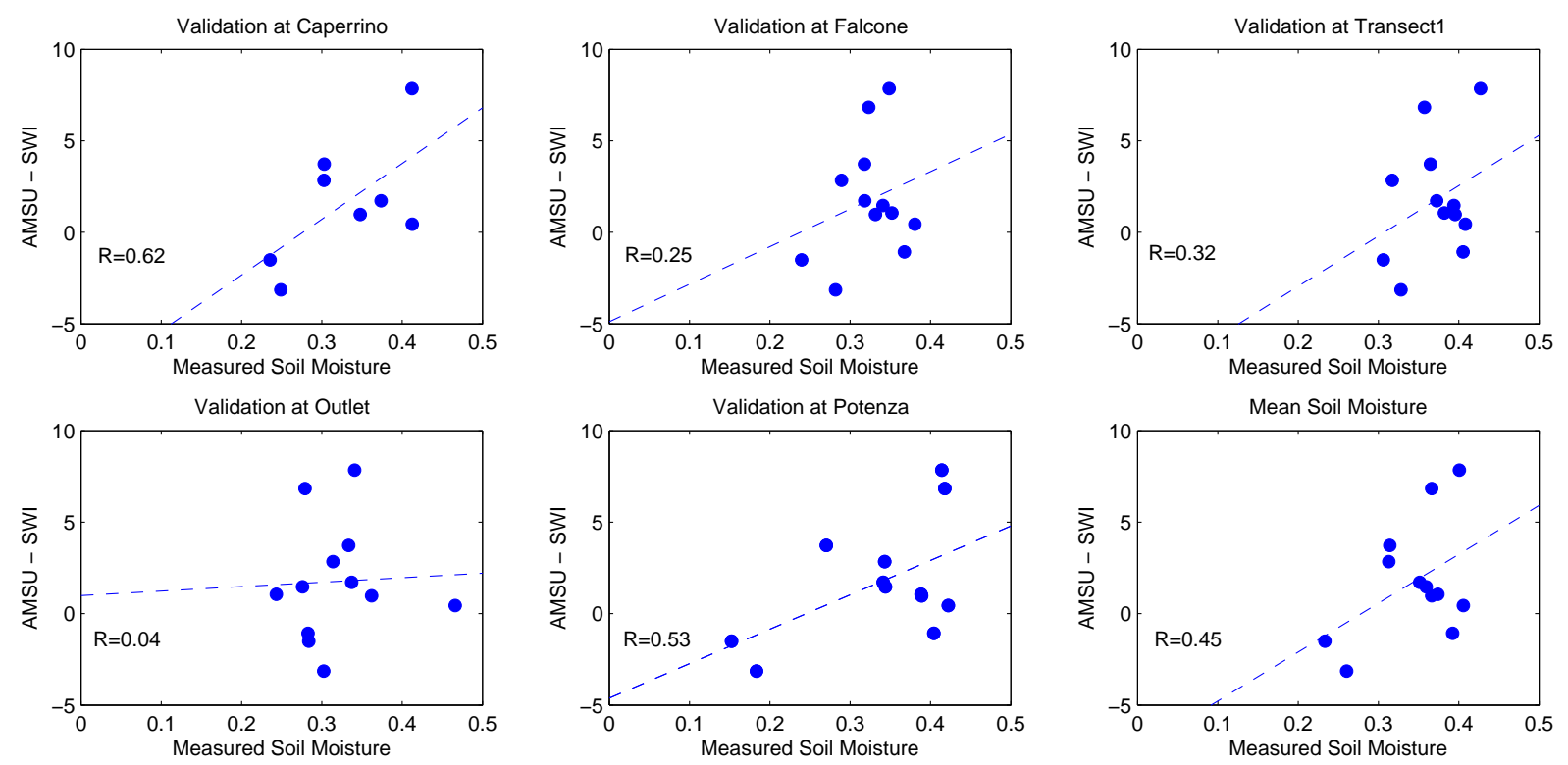

Fig. 2. Comparison between in situ SM $\left(\mathrm{m}^{3} \mathrm{~m}^{-3}\right)$ measured by TDR and the AMSU SWI $(\mathrm{K})$ at the five sites studied herein and also with the mean value of SM obtained excluding the site at the outlet. The correlation in case is given in the panel in order to provide a better description of the coherence between the two measures.

is designed to describe the SM deviations from the expected values taking also into account its natural variability. For this reason, SWVI is compared with a soil moisture variation (SMV) index computed for the modelled $\left(\mathrm{SMV}_{\bmod }\right)$ data. Such an index has been derived analogously to SWVI (see Eq. 2). The monthly mean and standard deviation of SM were used as reference value for the computation of the soil moisture variations. Such an operation was not feasible for the in-situ measurements because of the limited number of samples available for each month (i.e. March-AprilMay 2010).

It is necessary to underline that one AMSU pixel covers completely the basin area. Consequently, the time series obtained from the satellite sensors refer only to one pixel that was used to extract the data. Obviously, we preferred to simulate dynamics of SM at the basin scale because in this way we may better validate results of our hydrological application.

The first step of this study was to compare measurements acquired during the field campaign with remotely sensed data. Figure 2 shows the comparison between the measured SM and the SWI index for each of the investigated sites as well as the spatial mean. Looking at the figure it is possible to observe that the correlation seems to change from site to site, probably this might be related to the different land-soil units considered. On one hand, higher correlations are observed for the Monte Caperrino and Masseria Potenza sites, where a grass cover vegetation is present. On the other hand, sites characterized by a dense vegetation cover (i.e. forest) show lower correlation value. Such results confirm the negative impact of dense vegetation cover on the sensitivity of the
SM satellite retrieval. It is also important to observe that the site close to the basin Outlet is totally uncorrelated with the AMSU SWI. These data, as described in the previous section, were acquired with significant difficulties and are poorly representative of the actual SM conditions, for this reason they have not been considered for the computation of the spatial mean. Apart from the site close to the Outlet basin, a fairly good correlation is observed in all cases. The spatial mean SM displays a Pearson correlation coefficient of about 0.5 with highly scattered data. However, it is necessary to underline that the investigated period is characterized by a low number of significant rainfall episodes and the overall SM variability is mainly driven by a drying processes. This preliminary comparison shows a sufficient ability of the SWI to describe the state of the soil.

To investigate a longer period we adopted a hydrological simulation able to furnish soil moisture data over the entire basin. DREAM was used for this purpose and its performances have been tested against the measured streamflow with satisfying results, although this does not necessarily mean an accurate description of SM behavior (Grayson et al., 1992). For this reason, model was also validated using the SM measurements made during the field campaign (see Sect. 3.1). Fourteen maps of saturation degree were generated and plotted for those days providing an interesting description of the temporal and spatial variability of SM process (Fig. 3). Maps clearly show that in the considering period the relative saturation patterns reflect the main physical characteristics such as the soil texture and basin morphology. Moreover, the general behavior depicted by the measured SM (Table 1) is confirmed by the simulated SM 

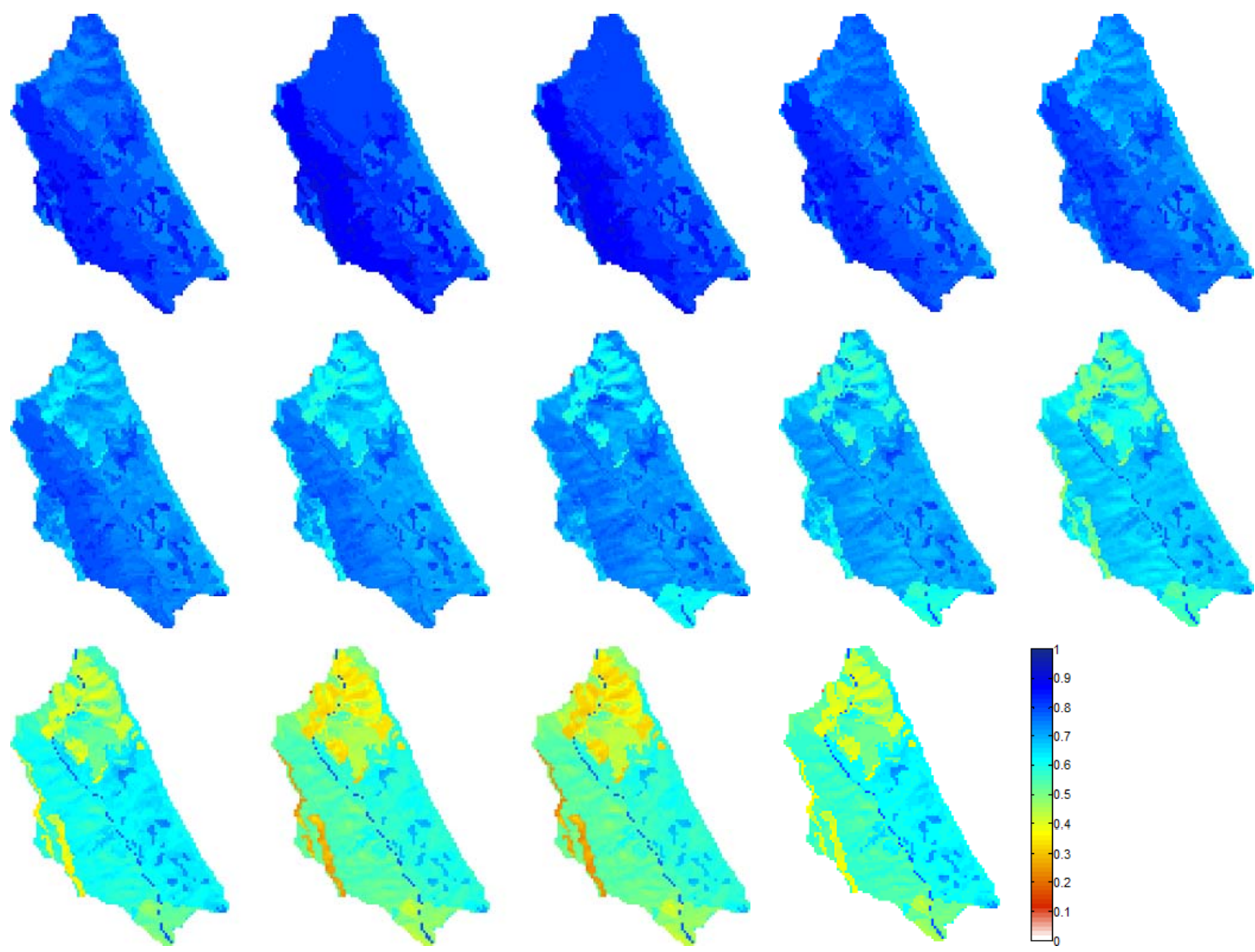

Fig. 3. Relative saturation degree maps obtained by the DREAM model for the days in which the field measurement have been carried out.

values obtained averaging the simulated SM in all pixels of the basin for the 14 days investigated (see Table 2). The comparison between the measured and simulated SM is given in Fig. 4, where the mean daily SM computed over each monitored sites is plotted as a function of the measured values. The comparison was in general satisfying with the exception of the site close to the basin Outlet. This result confirms the ones already discussed and it might be related to the sampling difficulties experienced during the field campaign. The difference between results achieved for grass covered and forested sites is reflected by the correlation in each case. The forested sites generally show a lower correlation than grass covered ones. This result is probably related to the control volume for the soil water balance equation. In fact, these sites are characterized by thicker soils $(150-180 \mathrm{~cm})$ that tend to modulate SM fluctuations and may differ significantly from the surface measurements taken at $0-30 \mathrm{~cm}$ of depth.

In a further step of this work, a direct comparison between the SWI, SWVI (both filtered and not) and the modeled SM was carried out to assess their capabilities in describing soil moisture variability for the investigated area during the analyzed period (Figs. 5 and 6). Focusing first on not filtered data, results of the comparison between SWI and the modeled SM, and SWVI and SMV mod are plotted in Figs. 5a and 6a. As a general remark, results show a limited ability for both AMSU-based indices to describe the modeled mean SM values. This is certainly due to the fact that the SM retrieved from satellite refers to the first top layer of soil, while the simulation made by DREAM refers to a control volume much larger, ranging from $50 \mathrm{~cm}$ to $180 \mathrm{~cm}$. Moreover, it must be stressed that the SWVI only describes the statistical fluctuations of the measured parameter, representing a white noise signal in absence of significant perturbing events. Thus, no significant correlation is expected as far as all the data-set is considered.

To improve the effectiveness of the remotely sensed time series, it is useful to apply a low pass filter like the one introduced in Eq. (3). Figure 5b shows the comparison between the modeled SM and the AMSU SWI*, while Fig. 6b shows the comparison between the modeled SM variation $\left(\mathrm{SMV}_{\mathrm{mod}}\right)$ and the SWVI*. In both cases, the parameter, $T$, of the filter was calibrated with the data, obtaining a value of $T=52$ days in the first case and 64 days in the second, which are in agreement with those obtained in a previous study (Lacava et al., 2010). The correlation between AMSU SWI* modeled SM significantly increases (as summarized in Table 3) up to 0.86 , while a slightly correlation was observed

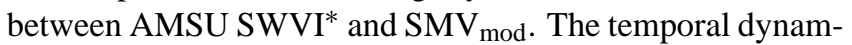
ics of SM simulated by DREAM and the AMSU based - 

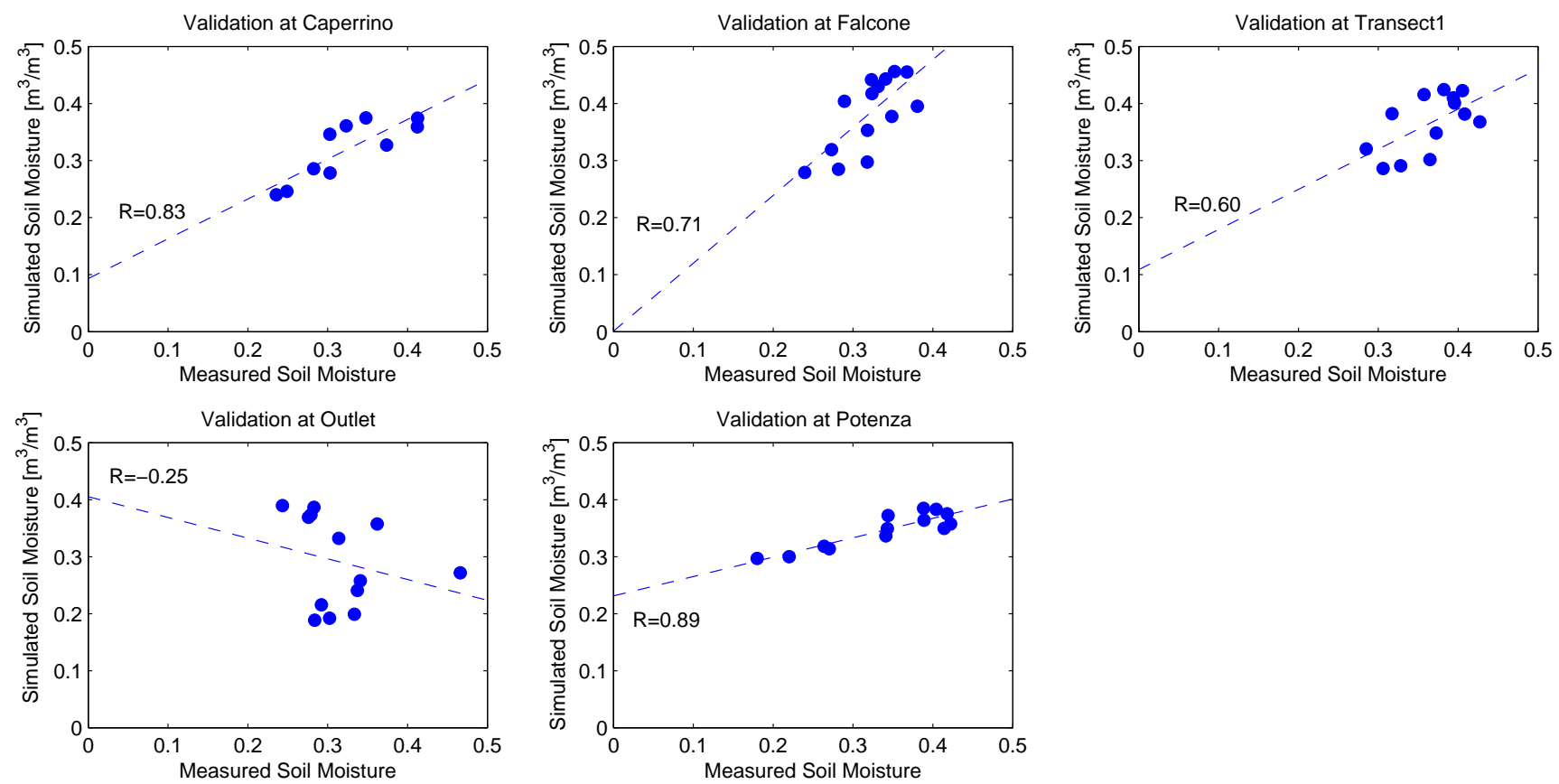

Fig. 4. Comparison between the simulated and measured $\mathrm{SM}\left(\mathrm{m}^{3} \mathrm{~m}^{-3}\right)$ in the five monitored sites during the field campaign.

Table 2. Simulated values of the $\mathrm{SM} \mathrm{m}^{3} \mathrm{~m}^{-3}$ obtained by DREAM model during the period from 3 March 2010 to 18 May 2010 in each of the monitored sites.

\begin{tabular}{lccccc}
\hline & 3 Mar 2010 & 15 Mar 2010 & 17 Mar 2010 & 22 Mar 2010 & 26 Mar 2010 \\
\cline { 2 - 5 } M. Caperrino & 0.390 & 0.400 & 0.400 & 0.390 & 0.375 \\
M. Falcone & 0.444 & 0.454 & 0.454 & 0.444 & 0.428 \\
Transect 1 & 0.416 & 0.426 & 0.421 & 0.410 & 0.400 \\
M. Potenza & 0.376 & 0.386 & 0.381 & 0.371 & 0.366 \\
Outlet & 0.374 & 0.392 & 0.387 & 0.369 & 0.356 \\
\hline Spatial mean & 0.400 & 0.412 & 0.409 & 0.397 & 0.385 \\
\hline & 29 Mar 2010 & 2 Apr 2010 & 20 Apr 2010 & 26 Apr 2010 & 30 Apr 2010 \\
\cline { 2 - 5 } M. Caperrino & 0.361 & 0.346 & 0.375 & 0.356 & 0.326 \\
M. Falcone & 0.417 & 0.401 & 0.396 & 0.375 & 0.354 \\
Transect 1 & 0.390 & 0.380 & 0.380 & 0.369 & 0.349 \\
M. Potenza & 0.356 & 0.351 & 0.356 & 0.351 & 0.335 \\
Outlet & 0.347 & 0.333 & 0.270 & 0.257 & 0.239 \\
\hline Spatial mean & 0.374 & 0.362 & 0.355 & 0.341 & 0.320 \\
\hline & 6 May 2010 & 13 May 2010 & 14 May 2010 & 18 May 2010 & \\
\cline { 2 - 5 } M. Caperrino & 0.287 & 0.247 & 0.242 & 0.277 & \\
M. Falcone & 0.317 & 0.285 & 0.280 & 0.296 & \\
Transect 1 & 0.318 & 0.292 & 0.287 & 0.303 & \\
M. Potenza & 0.320 & 0.300 & 0.295 & 0.315 & \\
Outlet & 0.216 & 0.194 & 0.189 & 0.198 & \\
\hline Spatial mean & 0.291 & 0.264 & 0.259 & 0.278 & \\
\hline
\end{tabular}



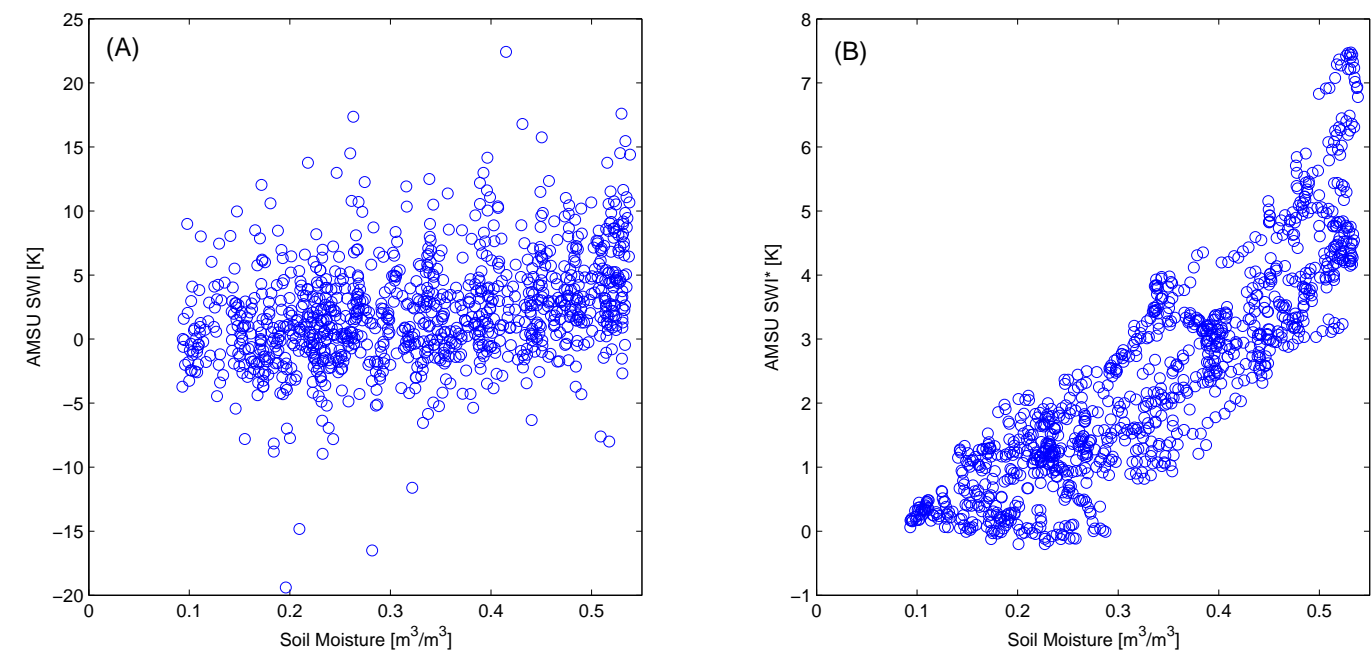

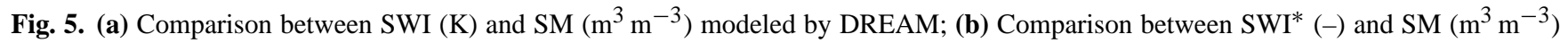
modeled by DREAM.
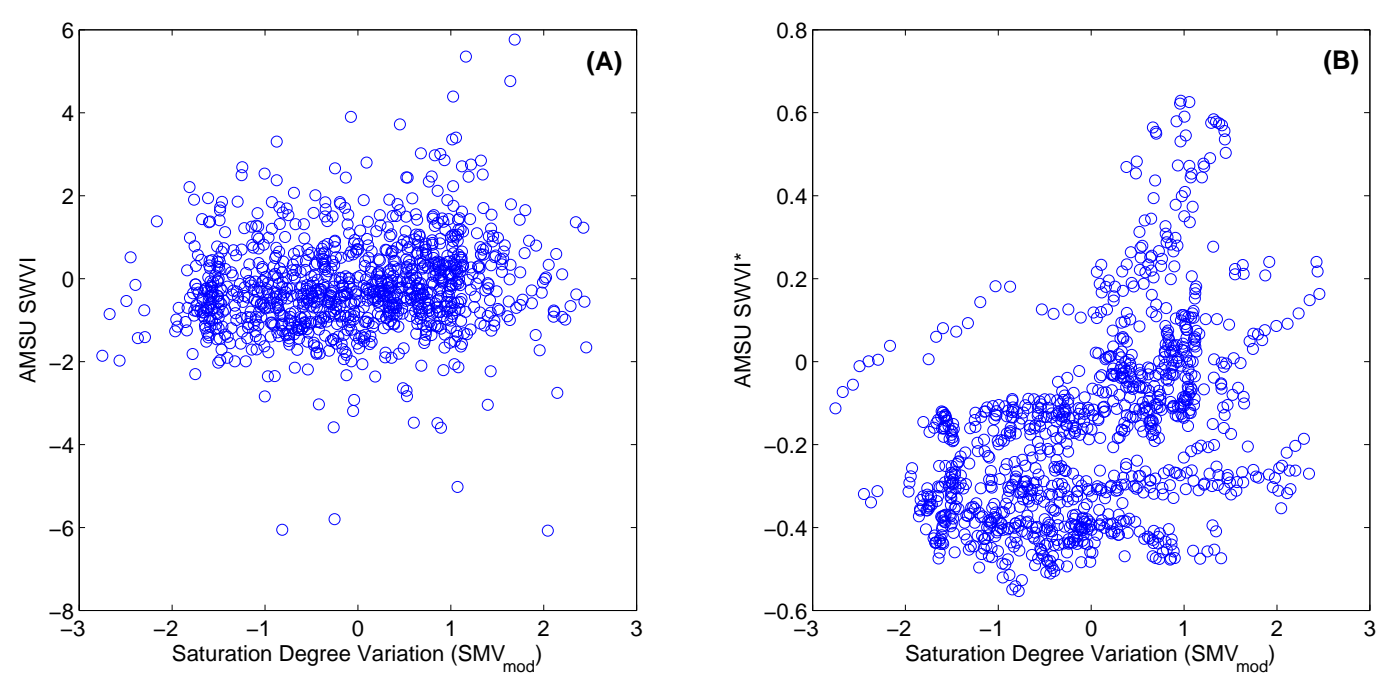

Fig. 6. (a) SWVI vs. modelled SM variation; (b) SWVI* vs. modelled SM variation.

SWI* are depicted in Fig. 7 using a double axis plot in order to keep the units of each measure. Here, one can appreciate the ability of $\mathrm{SWI}^{*}$ to mimic the general real behavior of SM although some short-time changes are not well identified by satellite-based retrieval. As a general comment, we observed that $\mathrm{SWI}^{*}$ is able to reproduce the seasonal fluctuations of SM, but is not able, at least in this case, to reproduce accurately the time series of SM, especially short time fluctuations. This challenge should be coped by the SWVI.

Within an operational context, information carried out by SWVI might furnish automatic and suitable indications about unexpected soil moisture variations in the time domain providing a support for alerting purposes and hazard assessment studies. So that, in the last part of this work we focused on the SWVI in order to better understand its ability to describe SM
Table 3. Summary of the DREAM simulation in terms of simulated SM and SMV vs. AMSU based indices.

\begin{tabular}{|c|c|c|}
\hline Comparison & $R$ & $T$ \\
\hline SWI vs. $\mathrm{SM}_{\bmod }$ & 0.36 & - \\
\hline SWI* $^{*}$ vs. $\mathrm{SM}_{\mathrm{mod}}$ & 0.86 & 52 \\
\hline SWVI vs. SMV $\bmod$ & 0.14 & - \\
\hline SWVI* $^{*}$ vs. SMV $\bmod$ & 0.44 & 68 \\
\hline
\end{tabular}

state and variations. As above cited, in "normal" conditions (i.e. in the absence of any significant perturbing event) SWVI only describes the statistical fluctuations of the measured parameter, which will not show a significant correlation as far 


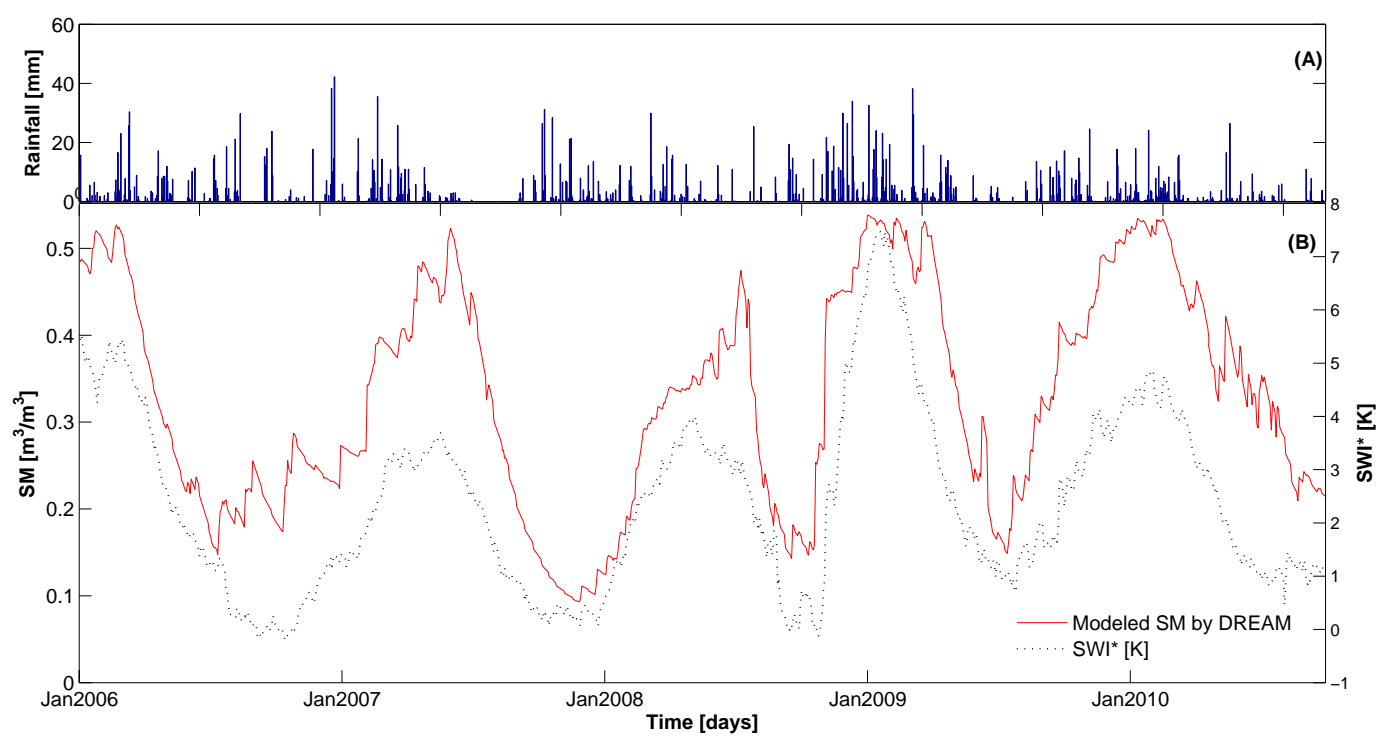

Fig. 7. (A) Time series of daily rainfall. (B) Comparison between the SM $\left(\mathrm{m}^{3} \mathrm{~m}^{-3}\right)$ simulated by DREAM model and the SWI* $(\mathrm{K})$ index as a function of time expressed in days. On y-axes one finds the SM on the left and SWI* on the right side.

Table 4. The Pearson correlation index between SM obtained varying the threshold from 0.5 up to 3.5 along with the significance of the correlation.

\begin{tabular}{lccccccc}
\hline Threshold & 0.5 & 1.0 & 1.5 & 2.0 & 2.5 & 3.0 & 3.5 \\
\hline$R$ & 0.08 & 0.14 & 0.34 & 0.42 & 0.41 & 0.55 & 0.81 \\
\hline$p$ & 0.19 & 0.10 & 0.03 & 0.01 & 0.06 & 0.07 & 0.047 \\
\hline
\end{tabular}

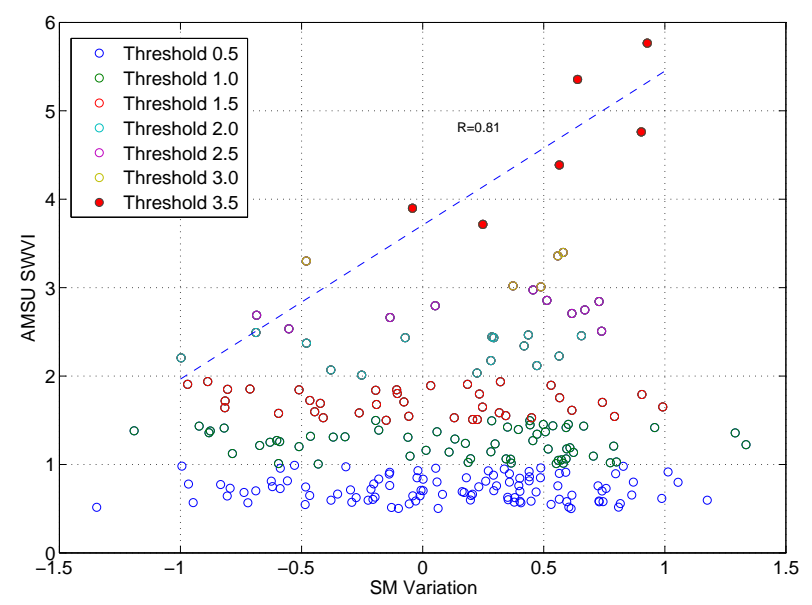

Fig. 8. Comparison between the variation of the simulated SM $\left(\mathrm{m}^{3} \mathrm{~m}^{-3}\right)$ and the AMSU based SWVI (-) index exceeding the thresholds ranging from 0.5 to 3.5 .

www.hydrol-earth-syst-sci.net/15/2839/2011/ as all the data-set is considered. More interesting should be to investigate only SWVI values above a given threshold. In particular, we were interested in analyzing SWVI values possibly associated to the occurrence of perturbing events (high saturation state related to intense precipitation episodes). As a consequence, the SWVI values above selected thresholds were compared with the relative variation of simulated SM. For this purpose, we adopted threshold values of SWVI ranging from 0.5 up to 3.5 observing an increase of the correlation with the threshold, as shown by the results reported in Table 4, where we also reported the significance of the correlation. In particular, correlation coefficient systematically increases as far as threshold increases up to a value of 0.81 . As previously stated, the values reported in the table are obtained discarding the pixels acquired at zenith angle $>50^{\circ}$. Discarding the pixels acquired at a zenith angle $>45^{\circ}$ a slightly increase in the correlation relative to each threshold is observed confirming the impact on the signal of the spurious effects arising from side view acquisition (Karbou et al., 2005). A deeper analysis of such effects will be carried out in future investigations.

The comparison with the SWVI and the relative change in SM is depicted in Fig. 8, where one can appreciate the changes in the reliability of SWVI with the increase of its values. Such results, here presented for the first time, seem to indicate a general strategy to support the management of the hydrogeological risk: SWI may be used to monitor the seasonal soil moisture pattern, while high SWVI values might be used to indicate soil moisture state at critical conditions. This aspect becomes more relevant considering that, at this moment, AMSU-A is operating on five NOAA satellites (1516-17-18 and 19) as well as on EOS-Aqua (since 2002) and on EUMESAT's Metop-A (since 2006), providing a temporal 
resolution of at least about $4-6 \mathrm{~h}$ at mid-latitudes. This high temporal resolution is a fundamental requirement for early warning activities related to flood prediction and forecasting in small to medium catchments, where the flood dynamics is very quick. In addition such a dense rate of acquisition will guarantee a global surface coverage even discarding data acquired at a zenith angle $>45^{\circ}$.

\section{Conclusions}

In this work, the reliability of AMSU-based indices has been investigated further in details using a field monitoring campaign and a long term hydrological simulation. On one hand, the in-situ SM has been measured using a portable TDR during a three months campaign taking 48 point measurements distributed in different sites of a river basin located in Basilicata region (southern Italy). Each site was chosen in order to provide a complete description of the dynamics of the different land-soil units of the basin. On the other hand, the hydrological simulation was used to describe basin dynamics over a temporal window of about $5 \mathrm{yr}$.

The AMSU-based indices adopted in this work are respectively the SWI and the SWVI index. They were used in their original version as well as filtered in the form of SWI* and SWVI* in order to account for the discrepancy existing between the skin satellite measurement, that obviously produces a time series with higher temporal variability, and the field measurements referring to the first $30 \mathrm{~cm}$ of soil or the simulations that are averaged over a depth variable between $50 \mathrm{~cm}$ and $180 \mathrm{~cm}$.

Generally speaking, the analysis over different land-soil units provided an interesting insight on the temporal dynamics of soil moisture that is significantly influenced by land cover. In particular, we observed a good agreement between measured or modeled SM with remotely sensed data in presence of shallow rooted vegetation meaning that the comparison between these data becomes more reliable when they refer to similar control volume as well as to less vegetated areas.

Results of the field campaign provided a preliminary description regarding the ability of SWI to describe SM fluctuations. In spite of the short period of observation, a certain degree of correlation between SWI and the in-situ SM measurements was observed.

These results were corroborated by the analyses carried out over the larger temporal window where the simulated SM have been compared with the remotely sensed data. In this case, it is particularly clear how well SWI may describes the SM seasonal fluctuations, especially after the application of a low pass filter. Nevertheless, SWI provides less efficiency in describing short time variations. As a final remark, it was found that SWVI can capture the SM variations with a precision that increases at the higher values of SWVI and may represent a good strategy to monitor the SM state for flood forecasting purposes. These findings address the use of AMSU maps for floods, inundations and all related fields in which real time forecasting is important.

Acknowledgements. Salvatore Manfreda gratefully acknowledge the support of the University of Basilicata.

Edited by: T. Moramarco

\section{References}

Albergel, C., Calvet, J.-C., de Rosnay, P., Balsamo, G., Wagner, W., Hasenauer, S., Naeimi, V., Martin, E., Bazile, E., Bouyssel, F., and Mahfouf, J.-F.: Cross-evaluation of modelled and remotely sensed surface soil moisture with in situ data in southwestern France, Hydrol. Earth Syst. Sci., 14, 2177-2191, doi:10.5194/hess-14-2177-2010, 2010.

Allen, R., Pereira, R., Raes, D., and Smith, M.: Crop evapotanspiration- Guidelines for computing crop water requirements, Irrig. Drin., Roma, 56, 1998.

Allen, R. G., Trezza, R., and Tasumi, M.: Analytical integrated functions for daily solar radiation on slopes, Agr. Forest Meteorol., 139, 55-73, 2006.

Basist, A., Grody, N., Peterson, T., and Williams, C.: Using the Special Sensor Microwave/Imager to monitor land surface temperatures, wetness, and snow cover, J. Appl. Meteorol., 37, 888-911, 1998.

Beven, K. J. and Kirkby, M. J.: A physically based, variable contributing area model of basin hydrology, Hydrol. Sci. Bull., 24, 43-69, 1979.

Blume, T., Zehe, E., and Bronstert, A.: Use of soil moisture dynamics and patterns at different spatio-temporal scales for the investigation of subsurface flow processes, Hydrol. Earth Syst. Sci., 13, 1215-1233, doi:10.5194/hess-13-1215-2009, 2009.

Brocca, L., Calice, G., Lacava, T., Melone, F., Moramarco, T., Pergola, N., and Tramutoli, V.: Soil moisture estimation through the AMSU-based soil wetness variation index (SWVI) for hydrological applications, Proceedings of the 33rd International Symposia on Remote Sensing of Environment, Sustaining the Millennium Development Goals, 1-2, 981-984, 2009.

Calvet, J., Fritz, N., Froissard, F., Suquia, D., Petitpa, A., and Piguet, B.: In situ soil moisture observations for the CAL/VAL of SMOS: the SMOSMANIA network, Proceedings of the International Geoscience and Remote Sensing Symposium, IGARSS, 1196-1199, 2007.

Calvet, J., Wigneron, J., Walker, J., Karbou, F., Chanzy, A., and Albergel, C.: Sensitivity of passive microwave observations to soil moisture and vegetation water content: L-band to W-band, IEEE T. Geosci. Remote, 99, 1-10, 2010.

Camps, A., Font, J., Vall-llossera, M., Gabarro, C., Corbella, I., Duffo, N., Torres, F., Blanch, S., Aguasca, A., Villarino, R., Enrique, L., Miranda, J., Arenas, J., Julia, A., Etcheto, J., Caselles, V., Weill, A., Boutin, J., Contardo, S., Niclos, R., Rivas, R., Reising, S., Wursteisen, P., Berger, M., and Martin-Neira, M.: The WISE 2000 and 2001 field experiments in support of the SMOS mission: sea surface L-band brightness temperature observations and their application to sea surface salinity retrieval, IEEE T. Geosci. Remote, 42(4), 804-823, 2004. 
Carriero, D., Romano, N., and Fiorentino, M.: A simplified approach for determining hydrologic behaviour and depth of soils at basin scale, J. Agr. Eng., 2, 1-10, 2007.

Castillo, V., Gomez-Plaza, A., and Martinez-Mena, M.: The role of antecedent soil water content in the runoff response of semiarid catchments: a simulation approach, J. Hydrol., 284, 114-130, 2003.

Colliander, A., Chan, S., Yueh, S., Cosh, M., Bindlish, R., Jackson, T., and Njoku, E.: Utilization of airborne and in situ data obtained in SGP99, SMEX02, CLASIC and SMAPVEX08 Field Campaigns for SMAP Soil Moisture Algorithm Development and Validation, Proceedings of the 11th Specialist Meeting on Microwave Radiometry and Remote Sensing of the Environment (MicroRad), 43-48, 2010.

Dobson, M. and Ulaby, F.: Mapping soil moisture distribution with imaging radar, In: Principles and Applications of Imaging Radar. Manual of Remote Sensing, edited by: Henderson, F. M., Lewis, A. J., and Ryerson, R. A., 3rd Edn., Wiley, New York, 3, 407433, 1998

Dorigo, W. A., Wagner, W., Hohensinn, R., Hahn, S., Paulik, C., Xaver, A., Gruber, A., Drusch, M., Mecklenburg, S., van Oevelen, P., Robock, A., and Jackson, T.: The International Soil Moisture Network: a data hosting facility for global in situ soil moisture measurements, Hydrol. Earth Syst. Sci., 15, 1675-1698, doi:10.5194/hess-15-1675-2011, 2011.

ESA: New global network validates SMOS soil moisture data, available at: http://www.esa.int/SPECIALS/smos/SEM9UI19Y8G_0. html, last access: 26 May 2011, 2010.

Escorihuela, M., Chanzy, A., Wigneron, J., and Kerr, Y.: Effective soil moisture sampling depth of L-band radiometry: A case study, Remote Sens. Environ., 114, 995-1001, 2010.

Famiglietti, J., Devereaux, J., Laymon, C., Tsegaye, T., Houser, P., Jackson, T., Graham, S., Rodell, M., and van Oevelen, P.: Ground-based investigation of soil moisture variability within remote sensing footprints during the Southern Great Plains 1997 (SGP97) Hydrology Experiment, Water Resour. Res., 35, 1839$1851,1999$.

Fiorentino, M., Manfreda, S., and Iacobellis, V.: Peak runoff contributing area as hydrological signature of the probability distribution of floods, Adv. Water Resour., 30(10), 2123-2134, doi:10.1016/j.advwatres.2006.11.017, 2007.

GCOS-138: Implementation plan for the global observing system for climate in support of the UNFCCC (2010 update), available at: http://www.wmo.int/pages/prog/gcos/Publications/gcos-138. pdf, last access: 26 May 2011, 2010.

Grayson, R. B., Moore, I. D., and McMahon, T. A.: Physically Based Hydrologic Modeling 2. Is the Concept Realistic?, Water Resour. Res., 28(10), 2659-2666, 1992.

Grody, N., Weng, F., and Ferraro, R.: Application of AMSU for hydrological parameters, in: Microwave radiomemetry and remote sensing of the earths surface and atmosphere, edited by: Pampaloni, P. and Paloscia, S., VSP, The Netherlands, 339-352, 2000.

Gu, S., Qiu, H., and Yang, Z.: Spring soil moisture retrieving by AMSU-A microwave remote sensing data, Clim. Environ. Res., 9(1), 43-53, 2004.

Hino, M., Odaka, Y., Nadaoka, K., and Sato, A.: Effect of initial soil-moisture content on the vertical infiltration process - a guide to the problem of runoff-ratio and loss, J. Hydrol., 102, 267-284,
1988.

Jackson, T. and Cosh, M.: SMEX02 watershed Vitel network soil moisture data, Walnut Creek, Iowa, National Snow and Ice Data Center, Digital media, Boulder, 2003.

Jackson, T. and Vine, D. L.: Mapping surface soil moisture using an aircraft-based passive microwave instrument: algorithm and example, J. Hydrol., 184, 85-99, 1996.

Jackson, T., Vine, D. L., Hsu, A., Oldak, A., Starks, P., Swift, C., Isham, J., and Haken, M.: Soil moisture mapping at regional scales using microwave radiometry: The southern Great Plains Hydrology Experiment, IEEE T. Geosci. Remote, 37, 21362151, 1999.

Jackson, T., Bindlish, R., Gasiewski, A., Stankov, B., Klein, M., Njoku, E., Bosch, D., Coleman, T., Laymon, C., and Starks, P.: Polarimetric scanning radiometer $\mathrm{C}$ - and $\mathrm{X}$-band microwave observations during SMEX03, IEEE T. Geosci. Remote, 43(11), 2418-2430, 2005.

Jackson, T., Cosh, M., Zhan, X., Bosch, D., Seyfried, M., Starks, P., Keefer, T., and Lakshmi, V.: Validation of AMSR-E Soil Moisture Products Using Watershed Networks, Proceedings of the International Geoscience and Remote Sensing Symposium IGARSS, 432-435, 2006.

Karbou, F., Prigent, C., Eymard, L., and Pardo, J.: Microwave Land Emissivity Calculation Using AMSU Measurements, IEEE T. Geosci. Remote, 43(5), 948-959, 2005.

Kerr, Y.: Soil moisture from space: where are we?, Hydrogeol. J., 15(1), 117-120, 2007.

Kerr, Y., Waldteufel, P., Wigneron, J., Martinuzzi, J., Font, J., and Berger, M.: Soil moisture retrieval from space: the soil moisture and ocean salinity (SMOS) mission, IEEE T. Geosci. Remote, 39, 1729-1736, 2001

Kerr, Y., Waldteufel, P., Wigneron, J., Delwart, S., Cabot, F., Boutin, J., Escorihuela, M., Font, J., Reul, N., Gruhier, C., Juglea, S., Drinkwater, M., Hahne, A., Martin-Neira, M., and Mecklenburg, S.: The SMOS Mission: New Tool for Monitoring Key, P. IEEE, 98(5), 666-687, 2010.

Kongoli, C., Pellegrino, P., Weng, F., and Ferraro, R.: Evaluation of the AMSU land surface temperature algorithm for skin and shelter-air temperature retrievals, Extended abstract presented at the 14th Conference on Satellite Meteorology and Oceanography, part of the 86th AMS Annual Meeting, 2006.

Lacava, T., Cuomo, V., Di Leo, E. V., Pergola, N., Romano, F., and Tramutoli V.: Improving soil wetness variations monitoring from passive microwave satellite data: the case of April 2000 Hungary flood, Remote Sens. Environ., 96-2, 135-148, 2005.

Lacava, T., Brocca, L., Calice, G., Melone, F., Moramarco, T., Pergola, N., and Tramutoli, V.: Soil moisture variations monitoring by AMSU-based soil wetness indices: a long-term intercomparison with ground measurements, Remote Sens. Environ., 114(10), 2317-2325, 2010.

Manfreda, S.: Runoff generation dynamics within a humid river basin, Nat. Hazards Earth Syst. Sci., 8, 1349-1357, doi:10.5194/nhess-8-1349-2008, 2008.

Manfreda, S., Fiorentino, M., and Iacobellis, V.: DREAM: a distributed model for runoff, evapotranspiration, and antecedent soil moisture simulation, Adv. Geosci., 2, 31-39, doi:10.5194/adgeo2-31-2005, 2005.

Margulis, S., McLaughlin, D., Entekhabi, D., and Dunne, S.: Land data assimilation of soil moisture using measurements from the 
southern great plains 1997 field experiment, Water Resour. Res., 38, 1299, doi:10.1029/2001WR001114, 2002.

Merz, B. and Plate, E.: An analysis of the effects of spatial variability of soil and soil moisture on runoff, Water Resour. Res., 33, 2909-2922, 1997.

Meyles, E., Williams, A., Ternan, L., and Dowd, J.: Runoff generation in relation to soil moisture patterns in a small Dartmoor catchment, Southwest England, Hydrol. Process., 17, 251-264, 2003.

Njoku, E., Wilson, W., Yueh, S., Dinardo, S., Li, F., Jackson, T., Lakshmi, V., and Bolten, J.: Observations of soil moisture using a passive and active low-frequency microwave airborne sensor during SGP99, IEEE T. Acoust. Speech, 40(12), 2659-2673, 2002.

Panciera, R., Walker, J., Kalma, J., Kim, E., Hacker, J., Merlin, O., Berger, M., and Skou, N.: The nafe-05/cosmos data set: towards smos soil moisture retrieval, downscaling and assimilation, IEEE T. Geosci. Remote, 46(3), 736-745, 2008.

Pasolli, L., Notarnicola, C., Bruzzone, L., Bertoldi, G., Della Chiesa, S., Hell, V., Niedrist, G., Tappeiner, U., Zebisch, M., Del Frate, F., and Vaglio Laurin, G.: Estimation of Soil Moisture in an Alpine Catchment with RADARSAT2 Images, Appl. Environ. Soil Sci., 2011, 175473, doi:10.1155/2011/175473, 2011.

Romano, N. and Palladino, M.: Prediction of soil water retention using soil physical data and terrain attributes, J. Hydrol., 265, 56-75, 2002.

Romano, N. and Santini, A.: Effectiveness of using pedo-transfer functions to quantify the spatial variability of soil water retention characteristics, J. Hydrol., 202, 137-157, 1997.

Rosnay, P. D. and Calvet, J.: SMOSREX: a long term field campaign experiment for soil moisture and land surface processes remote sensing, Remote Sens. Environ., 102, 377-389, 2006.

Santini, A., Coppola, A., Romano, N., and Terribile, F.: Interpretation of the spatial variability of soil hydraulic properties using a land system analysis, in: Modelling of Transport Processes in Soils at Various Scales in Time and Space, edited by: Feyen, J. and Wiyo, K., Wageningen Pers, Wageningen, The Netherlands, 491-500, 1999.
Schulze, R.: Transcending scales of space and time in impact studies of climate and climate change on agrohydrological responses, Agr. Ecosyst. Environ., 82, 185-212, 2000.

Scipal, K., Scheffler, C., and Wagner, W.: Soil moisture-runoff relation at the catchment scale as observed with coarse resolution microwave remote sensing, Hydrol. Earth Syst. Sci., 9, 173-183, doi:10.5194/hess-9-173-2005, 2005.

Singh, R., Oza, S., Chaudhari, K., and Dadhwal, V.: Spatial and temporal patterns of surface soil moisture over India estimated using surface wetness index from SSM/I microwave radiometer, Int. J. Remote Sens., 26(6), 1269-1276, 2005.

Tramutoli, V.: Robust AVHRR Techniques (RAT) for Environmental Monitoring theory and applications, in: In Earth Surface Remote Sensing II, edited by: Cecchi, G. and Zilioli, E., SPIE, 3496, 101-113, 1998.

Tramutoli, V.: Robust Satellite Techniques (RST) for Natural and Environmental Hazards Monitoring and Mitigation: Theory and Applications, Proceedings of Multitemp 2007, 2007.

Troch, P., Troch, F. D., Grayson, R., Western, A., Derauw, A., and Barbier, C.: Spatial organization of hydrological processes in small catchments derived from advanced SAR image processing: Field work and preliminary results, Proceedings of 3rd ERS symposium on Space at the service of our Environment, European Space Agency, SP-414, 93-97, 1997.

Vall-llossera, M., Camps, A., Corbella, I., Torres, F., Duffo, N., Monerris, A., Sabia, R., Selva, D., Antolin, C., Lopez-Baeza, E., Ferrer, J. F., and Saleh, K.: SMOS REFLEX 2003: L-Band Emissivity Characterization of Vineyards, IEEE T. Geosci. Remote, 43(5), 973-982, 2005.

Wagner, W., Lemoine, G., and Rott, H.: A Method for Estimating Soil Moisture from ERS Scatterometer and Soil Data, Remote Sens. Environ., 70, 191-207, 1999.

Zribi, M., Parde, M., Hauser, D., Fanise, P., Boutin, J., Albergel, C., Calvet, J., Crapeau, M., Dechambre, M., Kerr, Y., Baeza, E., Mialon, A., Reverdin, G., Ruis, A., Saleh, K., and Wigneron, J.: CAROLS campaigns 2009: First Results, Proceedings of the 11th Specialist Meeting on Microwave Radiometry and Remote Sensing of the Environment (MicroRad), 49-54, 2010. 